\title{
ENSINO MÉDIO INTEGRADO DO IF SERTÃO PE CAMPUS PETROLINA: desafios e possibilidades para uma práxis interdisciplinar de professores de ciências humanas
}

\author{
Fábio André Porto Alves \\ Janaina Guimarães da Fonseca e Silva²
}

\section{RESUMO}

O objetivo desse artigo consiste em analisar a elaboração do Roteiro de Sistematização da Reflexão e Trabalho Interdisciplinar em Ciências Humanas no IF Sertão PE Campus Petrolina, visando contribuir para ações reflexivas dos docentes sobre suas práticas pedagógicas e possibilitando ações interdisciplinares em seu locus de atuação. Trata-se de uma pesquisa de abordagem qualitativa, caracterizada por uma intervenção-ação, pois buscou uma modificação na situação investigada. A pesquisa foi realizada na IF Sertão PE Campus Petrolina, sendo os sujeitos envolvidos 08 professores e professoras que atuam no ensino médio integrado. Foram realizados 04 encontros de formação, sendo o último deles de avaliação da proposta de intervenção, materializada em um produto: o Roteiro de Sistematização da Reflexão e Trabalho Interdisciplinar. Os resultados encontrados demostram que: apesar dos docentes já terem executado em suas ações pedagógicas projetos interdisciplinares, pouco se caracterizavam como tal. Ao longo da intervenção, os professores e professoras buscaram participar efetivamente dos momentos presenciais de formação continuada. Mesmo nas ausências pontuais, devido principalmente à carga excessiva de trabalho que esses profissionais possuem, a rede social foi um elemento de fundamental importância, elevando o conceito de comunidade de aprendizagem. Apesar de considerarmos que o tempo para vivenciar os elementos que constituem o Roteiro, produto final desta investigação científica, ser exíguo para avaliarmos o alcance dos trabalhos interdisciplinares, desenvolvidos entre os professores participantes da pesquisa,

\footnotetext{
1 Mestre em Educação pelo Programa de Pós-Graduação Stricto Sensu Formação de Professores e Práticas Interdisciplinares (PPGFPPI) Mestrado Profissional em Educação da Universidade de Pernambuco UPE-Campus Petrolina(2017). Atualmente é Professor Efetivo do IF Sertão Pernambucano Campus Santa Maria da Boa Vista Tem experiência na área de ensino de História na educação básica e na formação de Professores em nível superior, pesquisas realizadas na linha de História Local e Regional, como também em Educação com ênfase na Educação Básica, no Ensino Superior (Formação de Professores) e Educação Contextualizada para Convivência com o Semiárido. Líder do GEPEPI IF Sertão PE (Grupo de Estudos e Pesquisas em Práticas Interdisciplinares do IF Sertão PE Campus Santa Maria da Boa Vista). Orcid id: http://orcid.org/0000-0002-3705-9693. E-mail: fabio_porto10@hotmail.com

2 Doutora em história pela Universidade federal de Pernambuco (2012). Professora adjunta da Universidade de Pernambuco, campus Mata Norte em Nazaré da Mata. No Campus Petrolina é membro permanente do Programa de Pós-graduação em Formação de Professores e Práticas Interdisciplinares (PPGFPPI). Orcid id: http://orcid.org/0000-0003-15185784. E-mail: guimaraes.janaina@gmail.com
} 
pensamos que foi atingido o objetivo, no que concerne à mudança de atitude e de postura frente a ações interdisciplinares em ciências humanas no Ensino Médio Integrado.

Palavras-chave: Reflexão. Formação Docente. Práxis Interdisciplinar.

\title{
INTEGRATED MIDDLE SCHOOL OF IF SERTÃO PE CAMPUS PETROLINA: challenges and possibilities for an interdisciplinary practice of teachers of human sciences
}

\begin{abstract}
The objective of this article is to analyze the elaboration of the Roadmap for Systematization of Reflection and Interdisciplinary Work in Human Sciences in the Campus Petrolina Campus, aiming to contribute to reflective actions of the teachers on their pedagogical practices and enabling interdisciplinary actions in their locus of action. It is a qualitative research, characterized by an intervention-action, because it sought a modification in the situation investigated. The research was carried out at the Sertão PE Campus Petrolina, with the subjects being involved 8 teachers who work in integrated secondary education. Four training meetings were held, the last one being the evaluation of the intervention proposal, materialized in a product: the Roadmap for Systematization of Reflection and Interdisciplinary Work. The results show that: although the teachers have already implemented interdisciplinary projects in their pedagogical actions, they were little characterized as such. Throughout the intervention the teachers and teachers sought to participate effectively in the face-to-face moments of continuing education. Even in the occasional absences, due mainly to the excessive workload that these professionals have, the social network was an element of fundamental importance, raising the concept of learning community. Although we consider that the time to experience the elements that constitute the Roadmap, the final product of this scientific research, is insufficient to evaluate the scope of the interdisciplinary work developed among the teachers participating in the research, we think that the objective regarding the change of attitude and attitude towards interdisciplinary actions in human sciences in Integrated High School.
\end{abstract}

Keywords: Reflection. Teacher Training. Interdisciplinary Praxis.

\section{ENSINO MEDIO INTEGRADO DEL IF SERTÃO PE CAMPUS PETROLINA: desafíos Y posibilidades para una práxis interdisciplinar de profesores de ciencias humanas}

\section{RESUMEN}

El objetivo de este artículo consiste en analizar la elaboración del Plan de sistematización de la reflexión y trabajo interdisciplinario en Ciencias Humanas en el IF Sertão PE Campus Petrolina, con el fin de contribuir a acciones reflexivas de los docentes sobre sus prácticas pedagógicas y posibilitando acciones interdisciplinares 
en su locus de actuación. Se trata de una investigación de abordaje cualitativo, caracterizada por una intervención-acción, pues se buscó una modificación en la situación investigada. La investigación fue realizada en el IF Sertão PE Campus Petrolina, siendo los sujetos involucrados 8 profesores y profesoras que actúan en la enseñanza media integrada. Se realizaron 4 encuentros de formación, siendo el último de ellos de evaluación de la propuesta de intervención, materializada en un producto: la Ruta de Sistematización de la Reflexión y Trabajo Interdisciplinario. Los resultados encontrados demuestran que: a pesar de que los docentes ya han ejecutado en sus acciones pedagógicas proyectos interdisciplinarios, poco se caracterizaban como tal. A lo largo de la intervención, los profesores y profesoras buscaron participar efectivamente de los momentos presenciales de formación continuada. Incluso en las ausencias puntuales, debido principalmente a la carga excesiva de trabajo que estos profesionales poseen, la red social ha sido un elemento de fundamental importancia, elevando el concepto de comunidad de aprendizaje. Apesar de considerar que el tiempo para vivir los elementos que constituyen el guión, producto final de esta investigación científica, ser exiguo para evaluar el alcance de los trabajos interdisciplinarios desarrollados entre los profesores participantes de la investigación, pensamos que se alcanzó el objetivo en lo que concierne al cambio de actitud y postura frente a acciones interdisciplinares en Ciencias Humanas en la Enseñanza Media Integrada.

Palabras clave: Refléxion. Formación del Profesorado. Praxis Interdisciplinaria.

\section{INTRODUÇÃO}

As demandas sociais e econômicas que surgiram para a sociedade brasileira, consequentemente, também para a educação, principalmente na década de 90 do século XX, aproximam a constituição de uma formação de professores estruturada em diretrizes que possibilitem a construção sólida, científica e técnica de profissionais para atuarem na educação básica. Partindo dessas demandas, constrói-se um saber inscrito em uma esfera crítica, reflexiva, dialética e preocupada com a adaptação da práxis às necessidades do meio de atuação do educador.

Nesse ínterim, a pesquisa emerge como meio para redimensionar a prática pedagógica dos professores, fundamentando a reformulação e/ou construção de políticas públicas que atendam aos anseios da parcela da população brasileira, marginalizada do processo educativo, especialmente, por não possuir contato com o meio escolar, devido a dificuldades inúmeras que são inerentes ao seu contexto de vida.

A Educação Básica no Brasil se apresenta como de fundamental importância para a construção pessoal, profissional, como também 
simbólica das pessoas, conforme elenca a Lei de Diretrizes e Bases da Educação Nacional (Lei 9394/1996), também conhecida como Lei Darci Ribeiro, em seu artigo 22: "A educação básica tem por finalidades desenvolver o educando, assegurar-Ihe a formação comum indispensável para $\circ$ exercício da cidadania e fornecer-Ihe meios para progredir no trabalho e em estudos posteriores." (BRASIL, 2001, p. 9).

A partir dessa assertiva, cabe uma questão: que educação é necessária para outro Ensino Médio? Sobre essa questão, Attico Chassot traz uma posição bem radical:

[...] devemos ensinar menos. Se educar é fazer transformações, não é com transmissão de informações que chegaremos lá. Esse novo Ensino Médio poderia experimentar ser cada vez menos disciplinar. Ao transgredir fronteiras estaremos assumindo posturas transdisciplinares. E, numa etapa mais audaciosa, mas mais realista, assumiremos uma escola interdisciplinar (CHASSOT apud AZEVEDO; REIS, 2013, p.11).

A partir desse contexto, elenca-se a interdisciplinaridade como temática fundamental na constituição de outro Ensino Médio necessário às nuances da contemporaneidade, em que pese à polissemia tão cara a esse conceito, o que determina em muitos casos no Brasil, que se realize todo tipo de experiência pensando-se estar fazendo interdisciplinaridade.

Para Fazenda (2008), a interdisciplinaridade encontra-se fundamentada nos âmbitos epistemológico, ontológico e praxiológico, traduzindo esses conceitos respectivamente em saber-saber, saber-ser e saber-fazer. Em termos de epistemologia, trata-se de exercitar a alteridade, por meio da qual objetividade e subjetividade se complementem; mais que a capacidade de relacionar-se, o ser humano se constitui efetivamente na relação com o outro.

No que tange à ontologia, a disciplina é deslocada para outra lógica de pensamento, cedendo lugar à preocupação com a pessoa, sua existência, seu modo de ser e de relacionar-se, buscando a eliminação das barreiras entre as disciplinas.

A perspectiva da práxis encara o pensamento da interdisciplinaridade não como a receita que resolverá todos os problemas do processo de 
ensino e aprendizagem, bem como aqueles relacionados à Epistemologia, mas sim, como afirma Fazenda (2008, p. 53), "Ela é compreendida como possibilidade de uma reflexão mais adequada sobre 0 homem e suas relações, seja consigo, com o outro, com o conhecimento e com o mundo".

Nesse contexto, essa investigação tem como temática fundamental: "Ensino Médio Integrado do IF Sertão PE Campus Petrolina: desafios e possibilidades para uma práxis interdisciplinar de Professores de Ciências Humanas". A proposta foi desenvolvida no IF Sertão PE Campus Petrolina, Instituição localizada no Sertão do São Francisco e que se constitui como referência de ensino, pesquisa e extensão, base para uma experiência de redimensionamento da prática pedagógica dos Professores da área de Ciências Humanas que atuam no Ensino Médio Integrado deste Campus, promovendo uma sistematização da prática de maneira interdisciplinar e que esta seja vivenciada também de forma contínua durante o ano letivo e não apenas pulverizada em projetos esporádicos.

Diante desse entendimento, a problemática que orientou a execução do trabalho investigativo fundamentou-se nos seguintes questionamentos: Há no IF Sertão PE Campus Petrolina uma práxis interdisciplinar sistematizada e contínua durante o ano letivo, no que tange ao trabalho exercido pelos Professores das Ciências Humanas, do Ensino Médio Integrado? E caso ocorra, como construir conjuntamente possibilidades para 0 desenvolvimento de uma práxis interdisciplinar?

A partir das informações que foram colhidas no decorrer da pesquisa, bem como a análise e conclusões do processo de investigação, pretendeuse contribuir com a atitude em torno de uma reflexão-ação dos Professores da Instituição inscrita no conceito de uma práxis pedagógica interdisciplinar. Esta deve contribuir para a construção de outro Ensino Médio no Campus, necessário frente à profusão de mudanças da contemporaneidade, o que implica afirmar que o "O todo é algo mais que a soma de suas partes. O que quer dizer que o todo tem certo número de qualidades e de propriedades que não aparecem nas partes quando elas estão separadas." (MORIN, 2012, p.562).

Revista Exitus, Santarém/PA, Vol. 9, № 5, p. 448 - 474, Edição Especial 2019. 


\section{DELINEAMENTO DA PESQUISA}

Levando-se em consideração as demandas da sociedade, hodiernamente, assim como todos os fatores que a circunscrevem, e nesse contexto, inserindo a atuação docente, configura-se de suma importância a relação do Professor com o locus de sua atuação, numa construção de interações que possibilite não apenas os saberes do cotidiano dos alunos, como também o envolvimento desse conhecimento de vida com a ciência, numa perspectiva de atendimento às necessidades concretas que a realidade (social, econômica, política e cultural) propõe como desafios às demandas históricas de um determinado tempo e lugar.

Tendo em vista esse aspecto, como também o sentido de transformação da realidade observada, esse estudo é de base qualitativa. Nesse aspecto, como se estabeleceu uma investigação sobre as relações sociais visando a mudanças de atitudes e comportamentos dos participantes (ANDRÉ, 2015) essa pesquisa se caracteriza como uma pesquisa-ação, sendo que Nóvoa (1992) também discute essa metodologia no âmbito da formação contínua de professores, o que corresponde ao cerne desse trabalho, ou seja, "[...] a prática docente em seu fazer cotidiano." (ANDRE, 2015, P. 8).

Dessa forma, o que se pretendeu foi dar oportunidade para que esses docentes passassem por um processo de reflexão que os levasse a (re)pensar suas práticas de ensino, fortalecendo as bases para uma atuação pedagógica interdisciplinar contínua e sistematizada, durante o ano letivo, afetando diretamente a qualidade do trabalho realizado pelos mesmos, na Instituição objeto da pesquisa, considerando o professor como sujeito de sua ação e não apenas um executor de planos pré-concebidos por pretensos iluminados pesquisadores da academia.

Dessa feita, há um processo de reflexão sobre a prática na qual o educador é o sujeito de sua ação, na via do autoconhecimento, definindo-o como produtor de conteúdo, elencando a necessidade de se refletir com ele um (re)apropriar de saberes que permitam reconstruir continuamente a sua prática docente na Instituição objeto da pesquisa (ANDRE, 2015). 
Baseando essa assertiva, também em Barbier (2000), para favorecer a construção de "Um educador filósofo que necessariamente religue a realidade social com a educação nova." (Informação verbal) ${ }^{3}$.

Nesse sentido, houve uma construção colaborativa com os docentespesquisadores, sendo que este pesquisador também está inserido no campo, pois pertence à comunidade acadêmica do IF Sertão PE atuando em outro campus, de um material que se consubstancia no produto desse trabalho de pesquisa: o Roteiro de Sistematização da Reflexão e Trabalho Interdisciplinar em Ciências Humanas, bem como a análise da experiência vivida junto à realidade do campus, levando-se em consideração principalmente o que afirma Fonseca (2002, p.34) "[...] a partir da compreensão, conhecimento e compromisso para a ação dos elementos envolvidos na pesquisa.", como também Thiollent (1988) na definição de pesquisa-ação:

A pesquisa-ação é um tipo de investigação social com base empírica que é concebida e realizada em estreita associação com uma ação ou com a resolução de um problema coletivo no qual os pesquisadores e participantes representativos da situação ou do problema estão envolvidos de modo cooperativo ou participativo. (THIOLLENT, 1988, p. 18).

Participaram dessa pesquisa 09 professores e professoras que atuam nas Ciências Humanas, no Ensino Médio integrado do IF Sertão PE Campus Petrolina, localizado na cidade de Petrolina-PE, região nordeste do Brasil. A escolha dessa área se deu, basicamente, pelas temáticas afins dos componentes curriculares que a compõem: História, Geografia, Filosofia e Sociologia; pela nossa formação inicial ser em História e por estarmos em constantes diálogos, bem anteriores ao momento da pesquisa, com esses educadores. Diálogos esses que sempre eram permeados pela ideia de integração dos saberes e de uma forma de poder sistematizar e operacionalizar esse pensamento.

\footnotetext{
${ }^{3}$ Conferência "O Educador como barqueiro de sentido e a Pesquisa-ação" Prof. Dr. René Barbier - Chefe do Departamento de Ciências da Educação/Universidade de Paris 8, SaintDenis. Tradutora: Profa ${ }^{a} r^{a}$ éleneLeblane UnB. $3^{\circ}$ Curso de Especialização em Educação em Educação Continuada e a Distância 1999-2000
} 
A adesão se deu após contatos mais específicos com esses atores em encontros individuais, explicando a intencionalidade do trabalho. A partir daí, eles aderiram pela disponibilidade e predisposição em participar. Para obter o livre consentimento dos participantes, foi elaborado termo, o qual previu a autorização da realização da pesquisa, primando pelo sigilo e anonimato das informações coletadas, sendo somente utilizadas cientificamente.

A coleta de dados foi realizada nas seguintes etapas:

1) análise exploratória do IF Sertão PE Campus Petrolina;

2) levantamento e diagnóstico de documentos norteadores das ações da instituição: PDI (Plano de Desenvolvimento Institucional); Projeto Político Pedagógico (PPP da Instituição); Projetos Pedagógicos dos Cursos do EMI ${ }^{4}$ (PPC'S);

3) apresentação de questionários e realização de entrevistas semiestruturados para cruzamento de dados coletados nos documentos e a prática descrita pelos professores. Resguardando a não identificação dos colaboradores e considerando os aspectos éticos da pesquisa, foram utilizadas letras do alfabeto para identificação dos mesmos;

4) realização de 4 encontros com os professores e professoras na perspectiva de formação continuada, os quais foram realizados após a devolução dos questionários respondidos e a realização das entrevistas para que se procedesse a análise dos dados e cruzamento das informações. Esses encontros foram divididos em:

$\left.1^{\circ}\right)$ apresentação dos objetivos da pesquisa; fundamentação teórico-metodológica, destacando a perspectiva da reflexão sobre a prática e a interdisciplinaridade; do produto que se pretendia elaborar de forma conjunta e a construção de um diagnóstico colaborativo das práticas já executadas;

\footnotetext{
${ }^{4} \mathrm{~A}$ partir desse momento do artigo será utilizada a sigla EMI para designar a modalidade de ensino estudada por essa pesquisa: Ensino Médio Integrado.
}

Revista Exitus, Santarém/PA, Vol. 9, № 5, p. 448 - 474, Edição Especial 2019. 
$2^{\circ}$ ) diálogos sobre a construção do hábito interdisciplinar na atuação cotidiana, experiências, problemas e possíveis caminhos para os desafios de se trabalhar com essa perspectiva;

$\left.3^{\circ}\right)$ elaboração do Roteiro de Sistematização da Reflexão e Trabalho Interdisciplinar, a partir das categorias elencadas pelos participantes nos encontros. Após a elaboração final do Roteiro os elementos constituintes deste, foram experienciados pelos docentes por um período de 27 dias;

$4^{\circ}$ ) após esse momento, foi realizado $\circ 4^{\circ}$ e último encontro no qual realizamos a análise final das experiências com o material elaborado atendendo a realidade do campus e a edição final.

Para a análise dos dados coletados, através da metodologia proposta, foi utilizado o método da análise de conteúdo em Bardin (2011), pois o mesmo se presta, segundo a própria autora, ao estudo "das motivações, atitudes, valores, crenças, tendências", o que facilita o processo de reflexão, intuição e propostas básicas de transformações nos limites das estruturas específicas e gerais. Triviños (1987) faz uma leitura da análise de conteúdo em Bardin e ressalta a importância deste método no campo da pesquisa qualitativa, da interação e cruzamento das informações dos materiais (documentos oficiais ou não e ainda das respostas ao questionário misto e às entrevistas semiestruturadas, que é o caso deste estudo).

Importante acrescentar que o projeto desta pesquisa foi aprovado pelo Comitê de Ética em Pesquisa (CEP), parecer $n^{\circ} 1.478 .213 / 2016$, da Universidade de Pernambuco, obedecendo aos requisitos da Resolução 466/2012 do Conselho Nacional de Saúde (CNS), sendo todas as informações mantidas em caráter sigiloso, preservando a identidade das pessoas avaliadas na investigação, cuja adesão foi formalizada por meio do Termo de Consentimento Livre e Esclarecido(TCLE). 
CAMINHO PERCORRIDO E A PERCORRER: VIVÊNCIAS E EXPERIÊNCIAS PARA A CONSTRUÇÃO DE UM ROTEIRO DE SISTEMATIZAÇÃO DA REFLEXÃO E PRÁXIS INTERDISCIPLINAR

\section{Descrição da experiência: avaliação conjunta com os colaboradores da pesquisa}

A elaboração do produto didático se deu conforme já elencado, e consistiu em um Roteiro de Sistematização da Reflexão e da Práxis Interdisciplinar dos Professores de Ciências Humanas, que atuam no Ensino Médio Integrado, no sentido de desenvolvê-lo de maneira contínua durante o ano letivo. Ele foi elaborado em colaboração com os docentes participantes do estudo, os quais foram de fundamental importância, devido, principalmente, ao conhecimento sobre o cotidiano do Campus em que atuam, bem como o perfil de alunos que possuem, o que foi levado em consideração.

A estrutura do Roteiro buscou contemplar o referencial teórico utilizado, não apenas na forma textual, mas também por meio de esquemas e mapas conceituais, abarcando os conceitos de professor reflexivo, práxis interdisciplinar e formação continuada, assim como contemplar a metodologia, ou seja, o caminho para a consecução dos objetivos almejados. Vale ressaltar que o roteiro não pretende ser um manual hermético em si mesmo. Ele busca se relacionar ao caso do IF do Sertão PE Campus Petrolina, com as possíveis limitações impostas pelo contexto institucional, descompasso entre o escrito nos documentos oficiais e a efetiva prática, dentre outros fatores.

Inicialmente, pretendíamos que o roteiro fosse vivenciado durante um bimestre, período em que no nosso entendimento, seria possível operar com um maior número de categorias de ação expressas no material. Contudo, o final do ano de 2016 se apresentou de forma conturbada, não apenas no IFSPE5, mas, em várias instituições de ensino no Brasil, devido a ocupações desses espaços educacionais pelos alunos. $O$ contexto principal das

\footnotetext{
${ }^{5}$ Instituto Federal de Educação, Ciência e Tecnologia do Sertão Pernambucano.
} 
ocupações foi caracterizado pela reforma do ensino médio, a maneira como estava sendo empreendida pelo governo federal e o fechamento de escolas na cidade de São Paulo pelo governo estadual, o que obrigaria os estudantes a terem de se locomover a grandes distâncias para exercer o seu direito à educação.

Nesse ínterim, o Campus Petrolina do IF Sertão PE passou 22 dias ocupado (de 24 de outubro de 2016 a 14 de novembro de 2016) pelos estudantes em protesto, sem a ocorrência de atividades regulares de ensino, mas com um calendário de ações voltadas aos debates em torno de questões nacionais, no que se refere à educação, mas também pautas internas desses alunos. Houve participação intensa dos professores que fizeram parte desta pesquisa em fóruns de discussão, o que confere a natureza desses momentos como ricos espaços de formação cidadã, nos quais os discentes puderam refletir sobre diversos aspectos sociais, econômicos e educacionais.

Esse evento atípico atrasou o cronograma que havíamos estabelecido no princípio do trabalho e causou alguns transtornos para a realização das entrevistas e dos encontros de formação, os quais eram planejados para ocorrer ainda em 2016, tendo em vista alguns docentes estarem bastante envolvidos no planejamento e execução das atividades ao lado dos alunos. Pensamos então que o mais prudente, em termos de execução da proposta, seria no retorno do semestre letivo em fevereiro de 2017, mesmo sabendo que isso traria eventuais prejuízos ao tempo para operacionalização da mesma, principalmente, no que tange ao trabalho interdisciplinar.

Ainda sobre essas dificuldades, o período de execução da proposta aconteceu no fim do semestre letivo 2016.2, o que diminuiu mais ainda a quantidade de dias que tivemos para a implementação. Mesmo assim, preferimos correr esse risco, a produzir resultados com uma ação empreendida às pressas, sem o devido cuidado com a construção do processo, com o que caracterizava o fenômeno estudado, como ele estava acontecendo e como tinha evoluído, bem como agir com honestidade 
epistemológica quanto à participação efetiva dos professores que se disponibilizaram com tanto empenho para a realização desta pesquisa.

Frente às intempéries vivenciadas na investigação científica, e que são naturais do percurso da construção de um pesquisador, na relação com o ambiente e atores pesquisados, redimensionamos o tempo de execução que os professores teriam para vivenciar a proposta. O que seria experienciado em um bimestre, agora teria de ser executado em 27 dias. Salientamos então aos docentes que procurassem viver ao máximo que conseguissem da experiência com as categorias do Roteiro, dentro do tempo que estávamos dispondo, sendo que poderíamos continuar trocando ideias também via rede social sobre a operacionalização.

Após esse período, nos encontramos para o quarto e último momento planejado de formação, nos dias 18 e 19 de maio de 2017, no qual fizemos a análise final das experiências. Além disso, aqueles que não puderem participar, presencialmente, enviaram suas percepções pelo grupo do Facebook ou via email. Esses espaços proporcionaram condições e elementos para chegarmos a conclusões mais confiáveis sobre as possíveis mudanças no pensar e no agir pedagógico dos professores e professoras participantes.

Nesse contexto, os docentes foram unânimes em afirmar que, devido ao tempo exíguo que tiveram, não puderem estabelecer trabalhos interdisciplinares com resultados que pudessem ser avaliados com segurança, sob o âmbito da fundamentação teórica que utilizamos. O que relataram, no geral, foram tentativas de início da operacionalização, a partir de ideias que surgiram nos próprios encontros de formação continuada.

É importante ressaltar que apesar dos docentes colocarem a questão do tempo de experiência com o roteiro ter sido curto, se for analisado o inicialmente programado, que pensamos não existir um "tempo ideal"6 para que ações pedagógicas interdisciplinares contínuas sejam vivenciadas. Acreditamos que é preciso trabalhar com o real, com os obstáculos postos,

${ }^{6}$ Grifo nosso.

Revista Exitus, Santarém/PA, Vol. 9, № 5, p. 448 - 474, Edição Especial 2019. 
entraves de toda ordem, claro que almejando o considerado ideal e desenvolvendo estratégias para alcançá-lo. É refletindo nos momentos de planejamento individual e coletivos, experienciando práticas interdisciplinares, compreendendo as particularidades que envolvem as turmas e avaliando os resultados das ações que podemos trilhar caminhos para um ensino mais integrado.

Dentro das possibilidades de vivência com o roteiro, os Professores $\mathrm{F} \mathrm{e}$ $\mathrm{H}$ refletiram e planejarem sobre o tema movimentos totalitários no período entreguerras e $2^{a}$ guerra mundial, estabelecendo o diálogo entre História e Filosofia, abordando também o crescimento de atitudes e grupos conservadores totalitários entre os jovens na contemporaneidade, no trabalho com a turma do $4^{\circ}$ ano de eletrotécnica.

Usando imagens, postagens de redes sociais e textos de apoio, os docentes desenvolveram a ideia. Para $O$ docente $H$, a experiência ficou prejudicada porque ele não teve como comparecer à apresentação do trabalho executado pelos estudantes devido a outra responsabilidade que precisou dar conta, valendo-se para isso das inferências e avaliações do professor F. Ele classifica que, mesmo confiando na avaliação do colega, não se sente confortável para afirmar se o produto dessa ação se consubstanciou como interdisciplinar, se os estudantes se apropriaram e compreenderam a transversalidade do tema para as duas áreas, no caso História e Filosofia, sabendo se posicionar sobre.

Acreditamos que o fator já elencado, de exiguidade do tempo, foi o entrave principal para a avaliação deste professor, o que enfatiza a necessidade de vivenciarmos o roteiro com maior espaço de tempo, possibilitando a constituição de elementos mais robustos de avaliação, no que diz respeito à prática interdisciplinar contínua. Entretanto, enfatizamos novamente que não há condições ideais para a operacionalização dessas ações, principalmente no contexto da educação brasileira, cujas disparidades são de diversos tipos e dimensões. O caminho para se alcançar essas condições é construído na práxis cotidiana, nas experiências, é por isso que acreditamos que os docentes devem experimentar, inovar e criar, 
sempre avaliando os resultados e refletindo com os pares sobre o que foi vivido, os pontos positivos e negativos, de que forma outros docentes podem utilizar a experiência.

Para ele, mesmo não sendo possível afirmar categoricamente isso, o valor maior do trabalho na mudança inicial de sua atitude, e na construção do seu habitus foi o estabelecimento do espaço de conversação, ressaltando a necessidade de ter isso, inclusive institucionalizado na Instituição para que "[...] nossas conversas possam convergir para a execução contínua da práxis interdisciplinar de fato." (PROFESSOR H, $4^{\circ}$ encontro de formação 18/05/2017).

Quando o professor $\mathrm{H}$ elenca o conceito de habitus, leva em consideração o que foi vivenciado nos momentos de formação continuada propostos a partir de sugestão da professora C: experienciar uma mudança, não apenas no hábito pedagógico em seu significado literal, do dicionário, mas fundamentando esse conceito em Bourdieu:

Por em evidência as capacidades criadoras, ativas, inventivas do habitus (que a palavra hábito7 não diz), embora chamando a atenção para a ideia de que este poder gerador não é o de um espírito universal, da natureza ou de uma razão humana, como em Chomsky, o habitus é um conhecimento adquirido e tem um haver, um capital (de um sujeito transcendental na tradição idealista), o habitus, a hexis, indica a disposição incorporada, quase postural -, mas sim, o de um agente em ação; tratava-se de chamar a atenção para o primado da razão prática [...] (BOURDIEU, 1989, p. 62).

Setton (2002) interpreta esse conceito como sendo capaz de conciliar a oposição aparente entre a realidade exterior e as realidades individuais. Capaz de expressar o diálogo, a troca constante e recíproca entre um mundo objetivo e o mundo subjetivo de individualidades. Um auxílio para apreender certa homogeneidade nas disposições, nos gostos, nas preferências de grupos e/ou indivíduos produtos de uma trajetória social parecida.

\footnotetext{
7 O significado de hábito no Dicionário OnLine de Português é: s.m. Mania; ação que se repete com frequência e regularidade; comportamento que alguém aprende e repete frequentemente.No Dicionário Aurélio o significado que se aproxima desse sentido é: prática frequente.
} 
Entretanto, o habitus não deve ser interpretado como sinônimo de uma memória sedimentada e imutável, "[...] é também um sistema de disposição construído continuamente, aberto e constantemente sujeito a novas experiências" (SETTON, 2002, p. 65).

Princípio de uma autonomia real em relação às determinações imediatas da "situação", o habitus não é por isto, uma espécie de essência a-histórica, cuja existência seria o seu desenvolvimento, enfim, destino definido uma vez por todas. Os ajustamentos que são incessantemente impostos, pelas necessidades de adaptação a situações novas e imprevistas, podem determinar, transformações duráveis do habitus, mas dentro de certos limites. Dentre outras razões porque o habitus define a percepção da situação que o determina (BOURDIEU, 1983, p. 106 apud SETTON, 2002, p. 65).

Dessa forma, o habitus é compreendido como produto de relações dialéticas entre uma exterioridade e uma interioridade, habitus visto de uma perspectiva relacional e processual de análise, capaz de apreender a relação entre indivíduo e sociedade. Ambos em processo de transformação (SETTON, 2002).

A partir dessa premissa, o Professor H (2017) frisou também que uma mudança mais ampla demanda tempo, "É como acordar de manhã para fazer alguma tarefa simples do dia a dia, aquela sonolência inicial, e com o decorrer do dia você vai desempenhando tudo. E como toda a estrutura de nossa formação inicial foi disciplinar, muitas vezes não saímos da zona de conforto para transcender momentos pontuais [...]", como o que ele estabeleceu, inicialmente, com o docente F. Ele acredita que se tivesse sido em outro momento do calendário acadêmico, o resultado seria outro.

No entanto, o professor $F$, que teve a oportunidade de avaliar 0 resultado da atividade executada com o professor $\mathrm{H}$ na turma do $4^{\circ}$ ano de eletrotécnica entende que houve, sim, uma produção interdisciplinar pelo que o grupo de alunos apresentou e enfatiza:

Talvez em alguns momentos da nossa carreira aqui no If a gente tenha trabalhado de forma interdisciplinar, mas não sistematizado e tão fundamentado como após essa formação continuada que tivemos. Eu preciso de outros elementos, de outros colegas. Eu não fiz meu plano de curso ainda não, eu quero ver o que que é possível, quero os colegas que estão nas turmas que eu estou, passar um

Revista Exitus, Santarém/PA, Vol. 9, № 5, p. 448 - 474, Edição Especial 2019. 
zapzinho, eu vou trabalhar esse tema e o que que é possível trabalhar também. $O$ professor $G$ vem fazendo isso com a gente, provocando a reflexão. Eu acho bonito isso, do ponto de vista do conhecimento. E quando eu falo com o professor $\mathrm{H}$ e digo que estou trabalhando o período entreguerras e movimentos totalitários, ele vem com uns textos que... porque a gente vê da perspectiva histórica e ele traz a perspectiva de se ver isso sob a ideia de poder. Eu não tinha percebido isso aí (PROFESSOR $F, 4^{\circ}$ encontro de formação 19/05/2017).

Ele afirma que na experiência com o docente $\mathrm{H}$, usaram o lúdico como ferramenta. Relata ainda que essa turma foi uma das que mais apresentou problemas durante todo o curso e que decidiram abolir a prova como instrumento de avaliação, pelo menos nessa unidade. "Nossas experiências nos dizem que quando a gente deixa o aluno mais livre, aí eu me remeto àquele vídeo do Ruy César Espírito Santo ${ }^{8}$ que a gente trabalhou aqui, a gente perde muito isso no ensino médio, ele ainda pode desenhar, sentar no chão. A gente tem que agir muitas vezes como a professora $C$ colocou, a gente tem que ser um pouco indisciplinado, deixar o aluno produzir, protagonizar, é extremamente fundamental" (PROFESSOR F, 2017).

Ele enfatiza também que se houvesse mais tempo, se não fosse fim de semestre, poderia ter orientado mais, estado mais perto das imagens que os alunos estavam escolhendo para a discussão. Mas com as imagens, os alunos deveriam traçar uma conotação histórica, filosófica e sociológica, saindo da cronologia, abrindo outras possibilidades. "Eles se desingessaram, se posicionaram, e os meninos mais resistentes foram o que mais se destacaram" (PROFESSOR F, 2017). Após a finalização do trabalho, o professor $F$ (2017) diz que refletiu sobre o bom resultado com a turma, questionando-se:

Será que um dos motivos que essa turma tenha desandado no curso não seja esse distanciamento que a gente provoca, objetivando em excesso a avaliação e os outros processos? É possível levar pra sala de aula, planejar, refletir sobre as ações, agora: dá trabalho. Mas isso é exercício, uma série deles, eu vivenciei aqui, o que foi bom o que foi ruim eu avalio, e outra, se foi possível naquela turma é possível em outra? O aluno do $4^{\circ}$ ano é uma coisa, o aluno do $1^{\circ}$ ano seja outra.

\footnotetext{
${ }^{8} \mathrm{O}$ professor se refere ao vídeo que trabalhamos no $1^{\circ}$ encontro de formação continuada, Pensar e Fazer Arte: a educação fragmentada. Entrevista com o professor Ruy César Espírito Santo da PUC do GEPI (Grupo de Estudo e Pesquisa em Interdisciplinaridade da PUC-SP).
}

Revista Exitus, Santarém/PA, Vol. 9, № 5, p. 448 - 474, Edição Especial 2019. 
Sobre essa experiência específica, entendemos que os docentes nela envolvidos conseguiram exercitar vários elementos que constituem o Roteiro elaborado: a reflexão dentro da perspectiva de Schön (2000), reflexão na ação, reflexão sobre a ação e reflexão sobre a reflexão na ação; o uso de espaços institucionais para o planejamento coletivo; a execução de uma ação interdisciplinar sistematizada, porque foi planejada previamente; superação das imposições dos conteúdos curriculares, pois se minimizou a relevância da cronologia e a turma, segundo o relato do docente, estudou outras perspectivas sobre o tema na integração entre História e Filosofia.

Nesse ponto, entendemos também, diante do conteúdo, que ocorreu a vinculação entre teoria e prática, principalmente, no que concerne ao arcabouço teórico que foi trabalhado nos encontros e a ação implementada por esses docentes. Assim também como a adequação à realidade do Campus Petrolina, pois o relato trouxe a preocupação de que as atividades podem ser variadas, mediante os anos das turmas $\left(1^{\circ}, 2^{\circ}, 3^{\circ}\right.$ ou $4^{\circ}$ ), e nesse contexto, houve uma sugestão de que as turmas possam ser divididas, com um professor ficando responsável por, no máximo, dois anos do segmento de EMI, ou seja, o professor F ficaria com as turmas de $1^{\circ}$ ano de história, o professor I com as do $2^{\circ}$ ano, e assim sucessivamente.

Outro ponto que pode ser levantado dessa experiência é a inventividade, a criatividade que a caracterizaram. Os docentes procuraram internalizar os pontos problematizados nas formações, possibilitando a reconstrução dos seus habitus (BOURDIEU, 1989), tendo em vista que não se propuseram apenas a mera repetição do que foi proposto, mas buscaram ampliar seus horizontes de conhecimento sobre as temáticas abordadas, contextualizando suas práxis, falando próximos das zonas de apropriação dos alunos.

Já a professora A, que no momento da vivência estava operacionalizando uma atividade de um projeto interdisciplinar que já havia sido planejado com um colega do curso de Licenciatura em Música, fora do que foi proposto na nossa pesquisa, entendeu que os encontros trouxeram formas alternativas de comunicação e a organização proposta foi bastante 
flexível, incluindo o uso de redes sociais para facilitar a comunicação, o que facilitou bastante a participação:

Fiquei bastante entusiasmada a partir da vivência das oficinas e do objetivo de pesquisa, pois apresenta possibilidade para que nós, professores do IF Sertão PE Campus Petrolina, possamos efetivar a prática de interdisciplinaridade a partir das concepções teóricas e metodológicas propostas. Apesar de estar envolvida em um outro trabalho que já havia sido planejado anteriormente e com um colega de outra área, entendo que consegui me valer de vários aspectos do roteiro, principalmente no que tange à reflexão, ao registro dessas reflexões, à fundamentação teórica sobre interdisciplinaridade e a questão da mudança de atitude para empreender a ação. Pois o empreendido é/será valoroso, pois, pela primeira vez acredito napossibilidade de realmente fazermos um trabalho interdisciplinar (PROFESSORA A, email enviado em 29/05/2017).

Ela ainda acrescenta que ficou clara a coerência entre o conteúdo e abordagem utilizados nas formações, com uma bibliografia atualizada, posição corroborada pelos outros participantes que se pronunciaram nos encontros ou via grupo de conversa no Facebook. "Qual é a contribuição social que fica dessa pesquisa? Eu acho que não pode ficar só aqui. Isso tem que continuar e temos que pensar numa forma de continuar" (PROFESSOR F. 2017). Essa foi a fala desse docente que provocou a formação de um grupo de estudo e pesquisa em interdisciplinaridade no Campus Petrolina, inicialmente, mas que poderia em certo momento se tornar intercampi, no qual pudéssemos fomentar e ampliar a reflexão e problematização sobre as categorias estudadas, no decorrer dessa intervenção-ação. Foi sugerido pelos professores que pudéssemos coordenar esse grupo e aceitar o desafio de puxar o debate em torno disso, o que foi aceito prontamente.

A sugestão de criação do grupo de estudos e pesquisas é mais um argumento que reforça a ideia de modificação da situação investigada, pois denota a disposição de continuar estudando, refletindo sobre suas práticas, aprofundando a discussão sobre a interdisciplinaridade e como podemos implementar mais ações integradoras, que não fiquem restritas ao que é dito pelo currículo, mas extrapolem a perspectiva das áreas do conhecimento, porém sem se esquecer de primar pela delimitação do 
campo de atuação de cada uma, não perdendo a conexão e a ideia do todo na relação com as outras áreas.

O professor $D$ reforça mais uma vez, visto que nas formações e na entrevista já havia elencado esse ponto, a importância da institucionalização dos espaços de reflexão para se acessar as experiências dos outros colegas, bem como exercer um planejamento coletivo, que propicie a execução de mais trabalhos interdisciplinares. "Eu não tô dizendo que a instituição tenha que baixar uma normativa dizendo: a partir de hoje trabalharemos de maneira interdisciplinar, mas que exista por parte da gestão uma legitimação institucional disso" (PROFESSOR D, 2017).

Ressaltamos que durante o início do semestre 2017.2 estavam sendo realizadas modificações com um novo regulamento das atividades docentes, o qual aumenta a carga horária mínima obrigatória de sala de aula de 08 para 14 aulas. Além disso, estava sendo implantado um sistema eletrônico de registro do plano individual de trabalho. Todos os professores que participaram da pesquisa se queixavam da forma como isso estava sendo implantado pela gestão e como estava gerando tumulto entre os docentes, principalmente, naqueles que estavam sem expectativa de atender ao requisito do mínimo de aulas. Sendo que, segundo eles, a pressão para o preenchimento desse formulário digital estava prejudicando o planejamento inicial do semestre.

A partir disso, entendemos a importância de se fazer uma devolutiva dos resultados desse trabalho para o IF Sertão PE Campus Petrolina, no sentido de que não apenas os professores que participaram da ação, mas também a direção geral, de ensino, coordenação da área propedêutica, núcleo de apoio pedagógico e professores de outras áreas, tomem conhecimento da ação empreendida e das modificações realizadas a partir dela. Mais do que isso, que essas instâncias de gestão estejam conscientes do seu papel para que as práticas pedagógicas não tenham um fim, nelas mesmas, mas possam também agir na resolução de questões que transcendem as atitudes, as responsabilidades do professor e as imposições 
legais de normativas institucionais, apesar de reconhecermos a importância delas para a organização das atividades.

"Uma outra coisa que preciso falar é que esse trabalho balançou... Balançou nossas estruturas, balançou de forma geral a gente que participou. Do que que a gente precisa, o que que a gente quer de fato fazer com a nossa ação." A fala do professor F (2017) foi corroborada por outros participantes, e aborda mais uma vez a modificação na situação em que a pesquisa atuou. "Nós vivemos a experiência após um intenso processo de construção teórica para chegar ao roteiro, e é disso que precisávamos para dar o pontapé inicial na busca de trabalhos interdisciplinares e isso foi proporcionado por essa pesquisa-ação" (PROFESSOR I, $20174^{\circ}$ encontro de formação).

Esse mesmo professor, que atua com a disciplina história, abordou, inclusive, o planejamento de uma atividade interdisciplinar com um professor de química do campus, explorando tecnologias usadas na $1^{\circ}$ guerra mundial, dentre elas o gás mostarda. A ideia é estabelecer o diálogo com o docente de química responsável pelas turmas em que ele atua para traçar um paralelo sobre o contexto da produção dessa arma química, sua composição, quais os efeitos, o porquê daqueles efeitos e o uso na $1^{\text {a }}$ grande guerra.

\begin{abstract}
Essa ideia veio justamente durante nossos encontros. E veja que a proposta é delimitada à nossa área de humanas, mas me veio essa ideia quando eu fui olhar o conteúdo programático. Eu tinha muito mais dificuldade, antes da apresentação desse projeto, com atividades interdisciplinares. Se alguém viesse falar comigo sobre algo desse tipo eu ia me esquivar. Hoje eu já tomei a iniciativa de procurar o professor de química, porque daqui a umas 3 semanas, 4 semanas nós vamos tá operacionalizando, entendeu? As formações, partir dos referenciais teóricos que nós usamos, fizeram que eu mudasse. Eu acreditava que era difícil e o trabalho realizado fez com que eu entendesse ser possível, a partir de um caminho sistematizado, para que haja a continuidade das ações interdisciplinares (PROFESSOR I, $4^{\circ}$ encontro de formação, 2017).
\end{abstract}

Pensamos que o mais importante, dentro dessa última colocação do docente I e da intencionalidade da pesquisa, é que não tivemos, em nenhum momento, a pretensão de uniformizar as práticas desses profissionais 
com o roteiro que foi elaborado, e sim, provocar a reflexão sob a égide das temáticas propostas. Tanto é que todos os participantes consideraram a ação positiva, despertando-os para a mudança de atitude frente à prática, reverberando em sua atuação política como professores e professoras, principal fundamento do conceito de práxis sengundo Freire (1981) e Gadotti (1998).

\section{CONSIDERAÇÕES FINAIS}

A contemporaneidade tem apresentado inúmeros desafios aos professores, no que diz respeito ao trato com as atividades de sala de aula e ao desenvolvimento do conteúdo, seja o curricular ou o que emana das relações e dissensões entre o sujeito e a sociedade. Nesse contexto, a educação se depara com transformações cada vez mais aceleradas, que flexibilizam as ações, até mesmo os princípios e valores de um ser. Nesse sentido, é necessária a busca por uma educação que não apenas privilegie o conteúdo em si das áreas do conhecimento, mas dimensione conexões entre essas áreas, estabelecendo ligações que frutifiquem não só na resolução de problemas específicos, mas na plenitude da vida dos sujeitos como cidadãos críticos, reflexivos, atuantes e protagonistas no meio social.

Ouço muito em diálogos com colegas, conferências, entrevistas, que vivemos um conflito geracional, e ouvimos sempre alguém dizer, principalmente um professor ou professora: "Na minha época não era assim". Não, não era! Até porque as coisas de fato mudam, as águas de um rio não são as mesmas hoje e amanhã, assim como a história também é uma construção que envolve mudanças, mas também, algumas permanências. Mas, voltando ao conflito, acredito sim que estamos vivendo um. Mas, nascer já é um conflito. Ele é natural em qualquer dimensão das relações sociais. O que precisamos entender como professores é que a compreensão do espaço e tempo de um jovem da segunda década dos anos 2000 não é a mesma que há 20 anos, quiçá há 10 anos, pois a apropriação dele sobre os objetos que constituem a sociedade é feita a partir de canais, os quais alguns de nós não tivemos acesso quando tinham a idade desses jovens. 
Pensamos, então, que o profissional atuante na esfera do ensino deve estar atento a essas mudanças. Estar atento a isso, no nosso entender, é elaborar um caminho para a reflexão sobre suas práticas pedagógicas, redimensionando suas ações, acessando os revisionismos teóricos que as fundamentam, estabelecendo pontes entre os temas que vivencie com seus alunos e as construções sociais que estejam sendo produzidas, tanto no âmbito local como no global, materializando o sentido do ato político de educar, de uma práxis pedagógica. Nesse sentido, a escola não pode ser considerada como simples espaço de transmissão de conteúdos, mas como um dos elementos que possibilitem a formação para a cidadania.

Nesse estudo, diante dos objetivos de analisar a formação dos docentes participantes, investigando colaborativamente a presença da interdisciplinaridade em suas práticas, foi possivel perceber que os professores que dele participaram, fazem uso de uma variedade de saberes acumulados ao longo de suas carreiras, fundamentados em teorias que se apropriaram ao longo da sua formação inicial e continuada, buscando efetivar uma educação cidadã.

Em que pese esses docentes já terem executado em suas ações pedagógicas projetos interdisciplinares, a análise do conteúdo das entrevistas e questionários possibilitou a inferência de que pouco se caracterizavam como tal, devido principalmente à falta de disposição de alguns durante a execução, apesar do conhecimento amplo sobre o conceito de interdisciplinaridade que apresentaram, o que gerava, na maior parte das experiências, um produto final sem a integração dos saberes das disciplinas que constituíram inicialmente as propostas.

A partir do objetivo de elaboração, de maneira participativa, do Roteiro de Sistematização da Reflexão e Trabalho Interdisciplinar, baseado na metodologia da pesquisa-ação, observarmos ao longo da intervenção que os professores e professoras buscaram participar efetivamente dos momentos presenciais de formação continuada. Mesmo nas ausências pontuais, devido, principalmente, à carga excessiva de trabalho que esses profissionais possuem, a rede social foi um elemento de fundamental 
importância, elevando o conceito de comunidade de aprendizagem. Comunidade essa que continua em intenso movimento na sala de conversa que criamos no Facebook.

Realizando a análise conjunta do material que foi elaborado e sua adequação à realidade do Campus, foi possível perceber que, ao longo do processo de pesquisa, ficou claro que os espaços de reuniões do Ensino Médio Integrado no IFSPE Campus Petrolina devem se caracterizar mais pela reflexão sobre os problemas de ensino nas turmas, como também as práticas exitosas dos professores e professoras, e não apenas, por informes e avaliações do conselho de classe. Além disso, os momentos de reflexão coletiva devem contar também com os integrantes do NAP (Núcleo de Apoio Pedagógico), estabelecendo uma parceira com os docentes na resolução das questões referentes às turmas ou a alunos especificamente. Essa é a dimensão do nosso trabalho que cabe à gestão da Instituição: proporcionar os espaços de reflexão também é tarefa de quem comanda as ações de ensino, não apenas proporcionar, mas acompanhar e avaliar o que é desenvolvido nesse sentido.

Nesse ínterim, a devolutiva dos resutados da pesquisa, aspecto solitado pelos docentes atuantes dessa pesquisa-ação, foi realizada no I Encontro de Educadores do IF Sertão PE, na mesa dialogal sobre Práticas Educativas Contemporâneas, evento ocorrido em outubro de 2018, no qual vários professores e servidores administrativos do ensino dos diversos campi, bem como diretores gerais e diretores de ensino tiveram acesso ao percurso do trabalho realizado e puderam expor as suas impressões num diálogo sobre possobilidades de operacionalização das práticas de reflexão e trabalho interdisciplinar de maneira sistematizada e contínua durante o ano letivo, um espaço maior de reflexão sobre os temas que foram trabalhados, as lacunas, os desafios e as possibilidades que se apresentaram, buscando efetivar com maior amplitude mudanças de atitude e postura no que diz respeito às práticas dos docentes.

Apesar de considerarmos que o tempo para vivenciar os elementos que constituem o Roteiro de Sistematização da Reflexão e Trabalho 
Interdisciplinar em Ciências Humanas no EMI do IFSPE Campus Petrolina, produto final desta investigação científica, ser exíguo para avaliarmos o alcance dos trabalhos interdisciplinares desenvolvidos entre os professores participantes da pesquisa no momento de execução, pensamos à luz das discussões nos encontros de formação e conectando-os ao fundamento teórico e metodológico escolhidos, que foi atingido parcialmente, o objetivo no que concerne à mudança de atitude e de postura frente a ações interdisciplinares em ciências humanas no Ensino Médio Integrado.

A justificativa principal que fundamenta essa conclusão está nas ações empreendidas, não apenas após as formações continuadas, mas também durante, com os participantes exercitando a criatividade e inovação, através da reflexão sobre suas práticas coletivamente, abrindo horizontes profícuos para trabalhos conjuntos, não apenas com aqueles que estavam participando dos eventos, mas até com professores e áreas que não faziam parte do objeto da pesquisa. Todavia, a parcialidade de consecução do objetivo ocorre porque é necessário um tempo maior de vivência nesse sentido para observarmos mudanças em termos de atitude e postura desses profissionais.

Os momentos de interação proporcionados pelo trabalho formativo foram importantes. E essa é outra justificativa para a conclusão anterior, para reunir esses docentes e levá-los a pensarem, avaliarem, redimensionarem suas práticas pedagógicas, a partir de um referencial teórico que fornecesse elementos cientificamente aceitos para legitimarem suas ações ou dessem subsídios para as reformularem. Sendo que, nas reflexões, surgiram outros motes que não diziam respeito à gestão das atividades de sala de aula especificamente, mas estão diretamente imbricados no sucesso dos resultados destas.

Como não conseguimos, devido aos fatores já elencados neste artigo, avaliar o alcance e as produções das ações interdisciplinares durante os 27 dias de experiência com o Roteiro, e por considerarem que esse trabalho não deveria ser finalizado com este texto e com o produto da nossa pesquisa-ação, os docentes sugeriram que pudéssemos criar e coordenar 
um grupo de estudo e pesquisa em interdisciplinaridade, que inicialmente seria efetivado no Campus Petrolina, mas à medida que fossem ocorrendo as construções, pudesse se tornar intercampi no IF Sertão PE e até com outras instituições. Essa ação tende a estabelecer uma ponte entre teoria e prática, como um laboratório de experimentação de atividades. A sugestão se mostrou deveras pertinente, pois todos demonstraram disposição em estudar e se aprofundar sobre a temática em exercício posterior à investigação através o Roteiro, até para que tenhamos mais elementos para avaliar o aspecto interdisciplinar que ele elenca e se serão necessárias adequações aos possíveis entraves.

Esse foi outro resultado que já foi alcançado, pois o grupo de pesquisa foi criado recentemente (setembro de 2018) na plataforma de diretórios de grupos de pesquisa do Cnpq, sendo que já obteve o certificado pela Pró Reitoria de Pesquisa do IF Sertão PE. O Grupo de Estudos e Pesquisas em Práticas Interdisciplinares, GEPEPI IF Sertão PE que possui a proposta de aprofundar reflexões e ações no âmbito dos estudos sobre interdisciplinaridade.

Assim sendo, consideramos que esta pesquisa contribuiu para ações reflexivas sobre a prática pedagógica dos professores que o experienciaram, propiciando a sistematização de suas reflexões com fundamento teórico reconhecido cientificamente e possibilitando ações interdisciplinares em ciências humanas no ensino médio integrado do Campus Petrolina do IF Sertão PE. As possibilidades para que se efetive uma práxis interdisciplinar sistematizada e contínua durante o ano letivo são alvissareiras, tendo em vista a disposição que os professores e professoras demonstraram, acreditando na real possibilidade de verem materializado um trabalho interdisciplinar.

A criação do grupo de pesquisa pretende levar a proposta aos outros Campi do IF Sertão PE e a outras instituições, no sentido de ser refletida, problematizada e vivenciada, para que tenhamos mais condições de avaliar seu alcance. Sempre lembrando que devem ser observadas as condições materiais, culturais, estruturais, de formação inicial dos professores

Revista Exitus, Santarém/PA, Vol. 9, № 5, p. 448 - 474, Edição Especial 2019. 
participantes, dentre outros aspectos, o que consubstancia o Roteiro em um elemento de natureza científica, que possa reverberar no meio acadêmico, mas que não fique restrito a ele e possua um movimento de imersão na atuação dos professores da educação básica brasileira.

Para atingir esses objetivos, deve-se pensar na formação inicial do professor-pesquisador, estimulando novas modalidades de formação e de uma área teórico-metodológica de pesquisa em educação, especificamente, sobre a formação de professores e prática pedagógica. Principalmente, porque se trata de modificação de posturas frente ao mundo, e não apenas de práticas pedagógicas, mas também dessas posições prepotentes e unidirecionais, sendo que se presume que estas práticas e posições foram forjadas, em sua grande parte, na formação inicial. Formação essa que, pela própria constituição da universidade brasileira eminentemente dentro da perspectiva de racionalidade técnica e de fragmentação do conhecimento predominantes ainda hoje, se contrapõe à característica expressa por Fazenda (1998), do profissional que define $\circ$ ser professor, predominantemente, em sua competência interdisciplinar expressa na forma como exerce a profissão.

\section{REFERÊNCIAS}

ANDRÉ, M. Ełnografia da prática escolar. Campinas, SP: Papirus, 2015

BARDIN, L. Análise de Conteúdo. 3a Ed. Lisboa: Edições 70, 2011.

BARBIER, R. UNB-FACULDADE DE EDUCAÇÃO. O Educador como barqueiro de sentido e a Pesquisa-ação. Disponível em:

<https://www.youtube.com/watch? $v=8 \mathrm{H} 2 \mathrm{BW} 06 \mathrm{Lk} 9 \mathrm{M}>$. Acesso em 09 de nov. 2016.

BOURDIEU, P. O poder simbólico. Bertrand Brasil, 1989.

BRASIL. LDBEN: Lei de Diretrizes e Bases da Educação Nacional. Lei ${ }^{\circ}$ 9394/96.Brasília: Câmara dos Deputados, 2001.

CHASSOT, A. Um prelúdio para outro Ensino Médio In: AZEVEDO, J. C. de; REIS, J. T. Reestruturação do ensino médio: pressupostos teóricos e desafiosda prática. São Paulo. Fundação Santillana, 2013. 
FAZENDA, I. O que é interdisciplinaridade (org.). São Paulo. Cortez, 2008.

FONSECA. J. J. S. Metodologia da pesquisa científica. Fortaleza. UECE, 2002. Apostila

FREIRE, P. Pedagogia do Oprimido, 9a ed. Rio de Janeiro: Paz e Terra, 1981.

GADOTTI, M. Pedagogia da Práxis. 2 ed. São Paulo: Cortez. Instituto Paulo Freire, 1998.

MORIN, E. A religação dos saberes: o desafio do século XXI (org). Tradução e notas, Flávia Nascimento. 10ª ed - Rio de Janeiro: Bertrand Brasil, 2012

NÓVOA, A. Formação de professores e profissão docente. In: NÓVOA, A. (Coord.). Os professores e a sua formação. Lisboa: Dom Quixote, 1992

THIOLENT, M. Metologia da pesquisa-ação. São Paulo. Cortez e Autores Associados, 1988.

TRIVIÑOS, A. N. S. Introdução à pesquisa em ciências sociais: a pesquisa qualitativa em Educação. São Paulo: Ática, 1987.

SETTON, M. da G. J. A teoria do habitusem Pierre Bourdieu: uma leitura contemporânea. Revista Brasileira de Educação. n. 20, p. 50-70, maio/ago 2002.

Recebido em: 15 de janeiro de 2019 Aprovado em: 15 de maio de 2019 